\title{
Analysis of the limited arbitrage based on behavioral finance
}

\author{
Zhuoran Chen \\ School of Professional Studies, New York University, New York 10012, USA \\ zhuoranchenelite@163.com
}

Keywords: limited arbitrage, behavioural finance, noise trading, market value

\begin{abstract}
In real financial market, the completely unlimited arbitrage does not exist. Based on the two theoretical cornerstones of behavioural finance, this paper discussed the development of the limited arbitrage theory. And the restricted factors of arbitrage are summarized based on behavioural finance.
\end{abstract}

\section{Introduction}

It has always been a controversial topic that whether the behaviour of assets price efficiently reflect the basic value or effected by the noise traders' irrational mentality. From the perspective of Friedman, rational investors can profit from the mistakes of irrational investors which eliminates the market pricing bias, therefore the assets price can reflect the basic value [1]. Then a large number of scholars developed this idea into the no-arbitrage theory. For example, assuming the fundamental value of the Ford company's share is $\$ 20$ per share, some irrational investors may sale this share with $\$ 15$ per share because of their pessimistic expectations of the company's future prospects. According to the efficient market hypothesis, rational investors can quickly realize this investment opportunity and buy the share in a low price. The pressure of buying the share of Ford will pull the price back to the basic value. The viewpoint of Friedman has drawn a lot of attention at the first time, but the no arbitrage assumption has stringent requirements on the market which has large discrepancy with real market, such as arbitrage risk free, no transaction costs, complete market, all securities have corresponding substitutes etc.

Traditional financial research tried to explain the financial markets assuming the investors are rational. In finance research, "rational" contains two layers of meaning. Firstly, investors' expectations are correct, the subjective prediction of future changes of unknown variable is consistent with actual changes. Secondly, the investment decisions made by investors 'expectations have wide acceptability. However, after years of research, it has been found that there are big differences between the results of empirical study and the traditional financial theory. The securities market, the average earnings and investors' behaviour cannot simply be explained by the traditional theory model, therefore comes to the behavioural finance.

Since the late 1980s, the study of behavioural finance theory has made rapid development. More and more scholars believe that the market does not exist completely unlimited arbitrage and the rationality traditional model. Even if rational traders exist, the asset prices also could be deviation. Therefore, economists believe that the market is limit arbitrage and begin to thoroughly research about it. The concept of limit arbitrage firstly proposed by Shleifer and Vishny in 1997. Barbers and Thaler think limited arbitrage theory is one of the basis of behavioural finance theory [2-3]. Limited arbitrage theory believes that the actual arbitrage is different from traditional arbitrage. In the real arbitrage, market system restricts the arbitrageurs in the first place, arbitrageurs will encounter all sorts of risks, and finally arbitrageurs itself also has its limitations, so it is possible that arbitrageurs suffer the loss even forced liquidation. 


\section{The theoretical cornerstones of behavioral finance}

According to the assumption of "rational man" and "perfect arbitrage" in modern finance. Behavioural finance is put forward two major theoretical cornerstones of its own. Firstly, analysis of investors' psychology and behaviour based on the cognitive decision making psychological research. This theory tries to explore how investors make decisions in the real world, rather than be supposed to make decisions. Secondly, the limited arbitrage theory. this theory believes that the arbitrage activities need money and take risks. In the real financial market, arbitrage cannot eliminate all the mispricing.

\subsection{The limited arbitrage theory}

In a market without friction, the price is equal to its basic value. Once the price deviates its fundamental value, an attractive investment opportunity is being created. In the point of Friedman and Fama, Arbitrageurs would immediately seize this opportunity thereby to correct the price deviation. However, there are a lot of arbitrage opportunities which are not being used in financial markets, such as closed-end funds. To explain this phenomenon, the concept of limited arbitrage theory is proposed which is that arbitrageurs' behaviours are limits, to correct this price deviation need cost and risk. The limited arbitrage theory becomes one of theoretical cornerstones of behavioural finance which describes all kinds of restrictions the arbitrageurs may encounter on the real market.

\subsection{The analysis of investors' psychology and behaviour}

The hypothesis of rational man has been run through the development of economics, the decision-making behaviour of investors is always the best without the consideration of environment and abilities etc. which is clearly do not conform to the reality. In order to study the ability of investors to make the right choice, and how do people misuse the Bayes rule or subjective expected utility issues, behavioural model needs to point out the extent that the irrational behavior of investors off the rational man assumption, and how do people misuse law and subjective expected utility. The answers can't be found in the framework of the existing economics. Therefore, economists begin to turn to psychology, using psychology research results to analysis of how investors form beliefs, preferences, and how to make a decision in the process of actual investment. And those psychology research can better explain the various phenomenon of financial markets, therefore analysis of investors' psychology and behavior based on the cognitive decision making psychological research becomes one of another cornerstone of behavioural finance.

\section{The limited arbitrage in financial market}

In the real financial market, arbitrage is restricted by many factors. The arbitrage behavior needs to make the correct quotation on asset prices, and consider various aspects such as the influence of market system and traders itself.

There are two main types of arbitrage in real market, one is relative value arbitrage, the other is convergence trading arbitrage. Relative value arbitrage get profit mainly from pricing differences between various investments products such as stocks, bonds, options and futures. While convergence trading arbitrage expects the price gap of different assets will go narrow, and adopts strategies of "buy low/sell high" to wait until the price convergence to get profit. In the real financial market, arbitrage is limited by many factors, asset prices need to be correctly evaluate, the effects of market system and traders itself are all need to be considered. Those limited factors can be summarized as follows.

\subsection{The fundamental risk}

Take Ford's share as example, its basic value is $\$ 20$ per share. While the pessimistic noise investors pull the price to $\$ 15$ per share. If the arbitragers buy in at $\$ 15$, the most direct risk they will face will be that a negative news about the basic value of Ford shares will cause stock price to fall further and cause big loss. Certainly, the arbitragers have already fully aware of this risk, so 
they will sale other stock (for example the GM) to replace while buy in the Ford's share. But the problem is a complete alternative stock tend to be rare, so it is impossible to completely eliminate the basis risk.

\subsection{The model risks}

The starting point of arbitrage is the discovery of arbitrage opportunities for mispriced securities. Investors must fully understand and can predict the basic factors affecting all arbitrage securities and its change. The price model is needed to consider those factors to accurate pricing securities. Then arbitragers can use models to guarantee the price and the basic value of the securities, and to decide whether or not to participate in arbitrage.

\subsection{The noise trader risk}

The noise trader risk firstly proposed by De Long [4]. Shleifer \& Vishny conducted in-depth research about the noise investors risk [2]. It refers to the risk that the price deviation arbitrageurs used to arbitrage could be expanded in a short term. Even if arbitrageurs found an ideal alternative equity, they still need to take the risk of stock price to fall further. As long as people think there are possibilities that the share price can deviate from the basic value, then someone will think that future price movements will have the possibility of expanding the deviation. And more research on noise trader risk is based on the influence on asset prices such as a certain type of investors overreact, trading is excessive, positive feedback traders, etc.

\subsection{The execution cost risk}

In the real world, financial markets are not as complete and perfect as traditional assumptions financial markets, there is existence of friction and the information is incomplete. The concept of execution cost risk is from the broad sense, it includes not only commission, bid-ask spread, etc. which are directly related to money, also includes cost of time and energy as well as the use of resources which used for seeking mispriced arbitrage opportunities. The cost also includes the corresponding risk. By studying 82 companies which the value of those are less than their own subsidiaries, Mitcheel, Pulvino and Stafford found that the contact between $30 \%$ of the sample is fragmented before the relative value deviation is corrected, and if the convergence path of the price and the basic value is smooth the professional arbitrage income will increase by $50 \%$ [5]. The uncertainty of income distribution and risk characteristics significantly limit arbitrage.

\subsection{The arbitrage risk under principal-agent relationship}

The arbitrageurs use their own funds are not the mainly strength in arbitrage market because of the limits of personal risk bear ability capital strength and professional skills. In the real market, most of the arbitrage fund is based on the principal-agent relationship. In most cases, the investors are not clear what specifically are arbitrageurs doing. But investors understand they will lost when prices deviate from the basic value. The lost will make them doubt the ability of arbitrageurs, therefore to refuse to increase capital, even divestment, even if the arbitrage profit expectations have increased greatly. Those movements are fatal for arbitrageurs, thus limits the arbitrageur's role of arbitrage in the financial markets. When arbitrageurs face a great opportunity, such as the investment securities price gap go bigger, the capital adequacy is the determinant of the success of arbitrage. However, the arbitrageur will face double restriction from both the market and the investors which restrict the arbitrage.

\section{Conclusion}

According to the arbitrage restricts discussed in the last part, if using the modern financial theory as the guidance in the real financial market, the arbitrage will face very serious risks. Economics the fund a law - the law of one price which is one of the found laws of economics sometimes is not established in financial markets. It is closer to the reality of financial markets when considering the transaction cost, information cost, fundamental risk, noise trader risk, etc. And it also helps us to get 
better understand market arbitrage. Although arbitrage in the financial markets is often inadequate, needs money and needs taking risks, but it still drives market to the direction of more efficient. Based on the in-depth research and analysis of the risks during the arbitrage process, the limited arbitrage theory provides a reasonable explanation for the long-term existence of the financial assets price deviation

\section{Reference}

[1]. Friedman M. The Case for Flexible Exchange Rates, in Essays in Positive Economics [M]. Chicago: The University of Chicago Press, 1953.

[2]. Shleifer A. and Vishny R. The limits of arbitrage [J]. Journal of Finance, 1997, 52: 35-55.

[3]. Wurgle J. and Zhuravskaya K. Does arbitrage flatten demand curves for stocks? [J]. Journal of Business, 2002, 75: 583-608.

[4]. Long De, Shleifer A., Summers L. H. and Waldmann R. J. Noise trader risk in nancial markets [J]. Journal of Political Economy, 1990, 98: 703-738.

[5]. Mitcheel M., Pulvino T. and Stafford E. Limited Arbitrage in Equity Market [J]. Journal of Finance, 2002, 57: 551-584 